\title{
A Review on Nonpharmacological Treatment of Diabetic Mellitus: Myth V/S Reality
}

\author{
Sandhrima Sudhakaran, Ateendra Jha, A.R Shabaraya \\ Department of Pharmacy Practice, Srinivas College of Pharmacy Valachil, \\ Farangipete Post, Mangalore, Karnataka, India \\ Corresponding Author: Sandhrima Sudhakaran
}

\begin{abstract}
There are many reasons for medical myths occur. Most often they are passed from one generation to another by word of mouth. The origins of some myths are difficult to find out. Understanding those myths and misconceptions in patients with diabetes is important in providing better care to those. ${ }^{1}$

Diabetes mellitus (DM) is a lifestyle related painless morbidity that produces complex behavior of an individual 'living with disease'. There is a strong influence in the life of those individuals during the treatment of illness. Understanding those myths and misconceptions, and providing education to those individuals and their caregivers are necessary. In the more recent effect of this lifelong disease many factors affect prognosis including education, occupation, attitudes, values, beliefs, and perceptions of need for optimum management, which are shaped over time by cultural and social exposures. ${ }^{2}$

Myths existing about diabetes in the public have become a major hurdle for its proper treatment and control. ${ }^{3}$
\end{abstract}

Key words: myths, diabetes and lifestyle.

\section{INTRODUCTION}

Diabetes can be defined as a metabolic disorder characterized by resistance to the action of insulin, inadequate insulin secretion, or both. Beta cells of the pancreas produce the hormone Insulin. The body pumps glucose from food into cells to produce energy there by regulates the blood glucose level. Sometimes glucose does not reach the cells and remains in blood because the body neither produces enough insulin nor utilizes secreted insulin well which in turn leads to increased levels of blood glucose. ${ }^{4}$

There are three types of diabetes they are type-I, type-II, and gestational diabetes. Type-I diabetes occurs when the immune system attacks and destroys the pancreatic beta cells and makes the body does not produce enough insulin. It is usually diagnosed in children and young adults. Type-II is the most common type of diabetes, which occurs most often in middle-aged and older people where the body does not utilize insulin well.

Gestational diabetes can be developed by some women during their pregnancy and is cured after the delivery. It has a greater chance of developing type-II diabetes later in life. Factors such as age (>45 years), family history of diabetes, overweight, physical inactivity, race, and certain health-related problems such as high blood pressure had chances of developing type-II diabetes. In medical history, diabetes has shown a great impact on the health-care sector that resembles the burden in diagnosing, treating and managing it in a prominent way. ${ }^{5}$

\section{METHODOLOGY}

From Google Scholar and PubMed search engine around 200 articles related to the term myth was got and out of which 50 have been reviewed and from that 25 article was included in the study. 


\section{Myths Regarding Risk Factor of DM}

One of the commonest myths among populations worldwide is being overweight or obese, will eventually develop type 2 DM. Being overweight is only a risk factor for developing this disease. There are also other important non-modifiable risk factors such as family history, ethnicity and age. But too many people think that overweight or obesity is the most important risk factor. Most overweight people never develop type $2 \mathrm{DM}$, and many people with type $2 \mathrm{DM}$ are at a normal weight or only moderately overweight. The understanding of the myths and misconceptions about diabetes mellitus is important. ${ }^{6,7}$

\section{Myths about Diet and DM}

'Eating too much sugar causes diabetes' or 'People with diabetes can't eat sweets or chocolate' or 'eating too much fruit is good for a person with diabetes' or 'consumption of bitter food is good for a person with diabetes' are some of myths regarding lifestyle factors leading to diabetes reported by ADA. ${ }^{8}$

It is evident that type 1 diabetes is caused by genetics and unknown factors that trigger the onset of the disease; type $2 \mathrm{DM}$ is caused by hereditary factors and lifestyle risk correlates. So, diabetic and "dietetic" diets generally offer no special benefit in health. ${ }^{9}$

The patients are usually provided a readymade diet chart instead of a tailor made diet plan that suits its economy, religious beliefs, ethnicity, availability of low glycemic foods, etc. In absence of proper scientific training of health care providers in their curriculum, nutrition has become an orphan chapter not taught by any specialty so the dietary advice from health care providers becomes more empirical than expected. ${ }^{10}$

\section{Myths about Complications of DM}

There is also a common myth that 'once a person develops a complication from DM there is nothing that can be done'. The patients and their caregivers are rarely provided scientific information such as conventional classification of acute and chronic complications (vascular and nonvascular complications). ${ }^{11}$

The vascular complications of DM are further subdivided into microvascular [retinopathy, neuropathy, nephropathy] and macrovascular complications [Coronary Heart Disease (CHD), Peripheral Arterial Disease (PAD), Cerebrovascular Disease (CVD]. Nonvascular complications include problems such as gastroparesis, infections, and skin changes. ${ }^{12}$

Many people with diabetes are not aware of what can be done to prevent worsening of their condition. For example, as long as it is detected early through regular yearly eye exams, diabetes eye disease can often be effectively treated with laser surgery, good blood sugar and blood pressure control to preserve vision for many years to come. ${ }^{13}$

\section{Realities in the Life of Persons with Diabetes}

Research groups have noted that hyperglycemia has been involved in the mechanism of DM associated cognitive dysfunction. Patients with type $2 \mathrm{DM}$ are at higher risk of developing dementia for reasons of neurodegeneration and or microvascular changes. ${ }^{14}$

Another observational study from various regions of India demonstrated that an imperfect positive correlation existed between the prevalence of diabetes and dementia. ${ }^{15,16}$

\section{Lifestyle Modifications in Diabetes}

Diabetic retinopathy is more common in patients with increased blood glucose level, therefore they should consult an ophthalmologists on regular basis. Patients with DM should quit smoking and avoid alcohol. The patients with smoking are at high risk of developing peripheral vascular disease which often leads to amputation of toes, feet or legs. Dialysis is most often with renal impairment, worsened blood sugar control when compared to that of in non-smokers with diabetes and even 
causes death especially due to stroke and heart attack. ${ }^{17}$

A regular checkup by health care providers is a very important factor. Prevention is better than cure. We could not change the gene the way it is, but we can change our lifestyle with slight modification in our daily activities which help in prognosis of the disease condition. ${ }^{18,19}$

\section{CONCLUSION}

Myths and misconceptions about diabetes are prevalent in our society among both diabetics as well as non-diabetics, and this can have consequences upon the health seeking behavior of the people. In this study education is shown to be associated with decreased belief in myths.

We need to educate people about this disease and its preventive as well as treatment options. A large proportion of people have myths regarding diabetes; males, having family history of diabetes mellitus and being illiterate, were identified as prone for believing in myths. Belief in spiritual treatment was also very common. Education serves as a protective factor; hence efforts should be made to promote education and health awareness regarding the disease with more emphasis on myths regarding diabetes mellitus. ${ }^{20}$

Acknowledgement: None

\section{Conflict of Interest: None}

\section{Source of Funding: None}

\section{Ethical Approval: Not Applicable}

\section{REFERENCES}

1. Rai M, Kishore J. Myths about diabetes and its treatment in the North Indian population. Int J Diabetes Dev Ctries. 2009 Jul-Aug; 29(3): 129-132. doi: 10.4103/0973-3930. 54290

2. Singh M, Pal R, Ranjan R, Sarkar G, Bharti DR, Pal S. Diabetes Mellitus: Myths and Reality. Journal of Krishna Institute of Medical Sciences (JKIMSU). 2017 Oct $1 ; 6(4)$.
3. Adler E, Paauw D. Medical myths involving diabetes. Primary care. 2003 Sep;30(3):60718.

4. Classification and Diagnosis of Diabetes: Standards of Medical Care in Diabetes2019. 2020.

5. Type 2 diabetes - Symptoms and causes [Internet]. Mayo Clinic. 2020

6. Fein Kohli, Price JF, Strachan MW, Frier BM. The impact of diabetes on cognitive decline: potential vascular, metabolic, and psychosocial risk factors. Alzheimer's research \& therapy. 2015 Dec;7(1):46.

7. Lazar MA. How obesity causes diabetes: not a tall tale. Science. 2005 Jan 21;307(5708):373-5.

8. 10 Diabetes Diet Myths [Internet]. Healthline.

9. Mann JI. Diet and diabetes. Diabetologia. 1980;18(2):89-95.

10. Sleiman D, Al-Badri MR, Azar ST. Effect of mediterranean diet in diabetes control and cardiovascular risk modification: a systematic review. Frontiers in public health. 2015 Apr 28;3:69.

11. Kannel WB, McGee DL. Diabetes and cardiovascular risk factors: the Framingham study. Circulation. 1979 Jan;59(1):8-13.

12. Fowler MJ. Microvascular and macrovascular complications of diabetes. Clinical diabetes. 2008 Apr 1;26(2):77-82.

13. Nathan DM. Long-term complications of diabetes mellitus. New England Journal of Medicine. 1993 Jun 10;328(23):1676-85.

14. Geijselaers SL, Sep SJ, Stehouwer CD, Biessels GJ. Glucose regulation, cognition, and brain MRI in type 2 diabetes: a systematic review. Lancet Diabetes Endocrinol 2015; 3(1): 75-89.

15. Velayudhan L, Poppe M, Archer N, Proitsi P, Brown RG, Lovestone S. Risk of developing dementia in people with diabetes and mild cognitive impairment. $\mathrm{Br} \mathrm{J}$ Psychiatry 2010; 196(1):3640.

16. Singh M, Raj D, Raina SK, Gandhi MK, Chander V. Using multistate observational studies to determine role of hypertension and diabetes as risk factors for dementia. $\mathbf{J}$ Neurosci Rural Pract 2016; 7(5):3-6

17. Chong S, Ding D, Byun R, Comino E, Bauman A, Jalaludin B, et al. Lifestyle changes after a diagnosis of Type 2 diabetes. Diabetes Spectr 2017;30:43-50. 
18. Khan MU. Lifestyle modification in the prevention of Type II diabetes mellitus. Oman Med J 2012;27:170-1.

19. Bhatia V, IAP National Task Force for Childhood Prevention of Adult Diseases. IAP national task force for childhood prevention of adult diseases: Insulin resistance and Type 2 diabetes mellitus in childhood. Indian Pediatr 2004;41:443-57.

20. Nisar N, Khan IA, Qadri MH, Sher SA. Myths about Diabetes Mellitus among non diabetic individuals attending primary health care centers of Karachi suburbs. J Coll Physicians Surg Pak. 2007 Jul 1;17(7):398-401.

How to cite this article: Sudhakaran S, Jha A, A.R Shabaraya. A review on nonpharmacological treatment of diabetic mellitus: myth v/s reality. International Journal of Research and Review. 2021; 8(7): 44-47. DOI: https://doi.org/10.52403/ijrr.20210708 